\title{
Research on ICFD Deep Test Technology Based on LabVIEW Applied to Nuclear Power Station Circuit Board
}

\author{
Liang-cai-Qi ${ }^{1,}$, , Ji-shi-Guan and Xin-cai-Chang \\ ${ }^{1}$ China Nuclear Power Technology Research Institute Co., Ltd. \\ aqiliangcai@cgnpc.com.cn
}

Keywords: Nuclear Power Station, ICFD, LabVIEW, Fault diagnosis

Abstract. This paper introduces a ICFD (In-Circuit Fault Dignosis) deep test method. According to making test plan of the partial functional module of circuit board, gathering the input and output in-circuit, and assess the performance of the board. This method improves the ICFD technology while it can only test components before. The paper demonstrates the test result of Nuclear Power Station(NPS) board.

\section{Introduction}

There are all kinds of circuit boards in NPS, the health of boards affect the safety of NPS. If only depending on people to repair faulted board, it is nearly impossible and it will spent many time and cost. The automatic testing can find the faulted position quickly and save plenty of data.

The ICFD(In-Circuit Fault Dignosis) technology is developed from ICT(In-Circuit Testing) technology[1] which combines LabVIEW, it's especially researched for NPS board faults diagnosis and faults locating.

Internationally, Korea NPS has established circuit board testing analysis platform, and has tested thousands of boards. The platform is very important for NPS safety, stabilization and economics.

In domestic, such as national defense, electron, railway and communication have used ICT technology to test board. In 2011, the technology was first introduced to NPS[2], but it only could test the components, while the functional parts couldn't be test.

\section{ICFD deep test method}

Analyzing the function of board, we can assess the performance of board according to testing the partial function module. As to boards with operational amplifier, testing the amplifier function.

1) Noise Test

Testing the amplifier noise output, we set the inverted input and non-inverted input 0 voltages at the same time via 13070 platform, then capture the output of operational amplifier.

2) Magnification Times Test

Some operational amplifier in board play a magnification part, testing the magnification times can assess the performance of the function. Setting the input a certain voltage V1, then capture the output $\mathrm{V} 2$, we can get the magnification times from V2/V1.

3) Variation SignalTest

Variation signal testing can test the following the change ability of operational amplifier. Setting the input a sine-likewise wave, then capture the output.

4) Other Test

Besides the methods introduced above, according to the different function of boards, we can test the voltage, wave, frequency and so on to assess the performance and find the fault.

Due to the number of input and output is limited, so we intrduce NI device to send and receive signals, and process data with LabVIEW. 


\section{Case Study}

There is a kind of circuit board used in NPS, the amplifier A1 plays a magnification part, the magnification times is 1 . Testing it with deep testing method, noise testing, magnification times testing and variation signal testing.

Setting the two inputs as 0 voltages, capturing the out, the result is shown in figure 1.

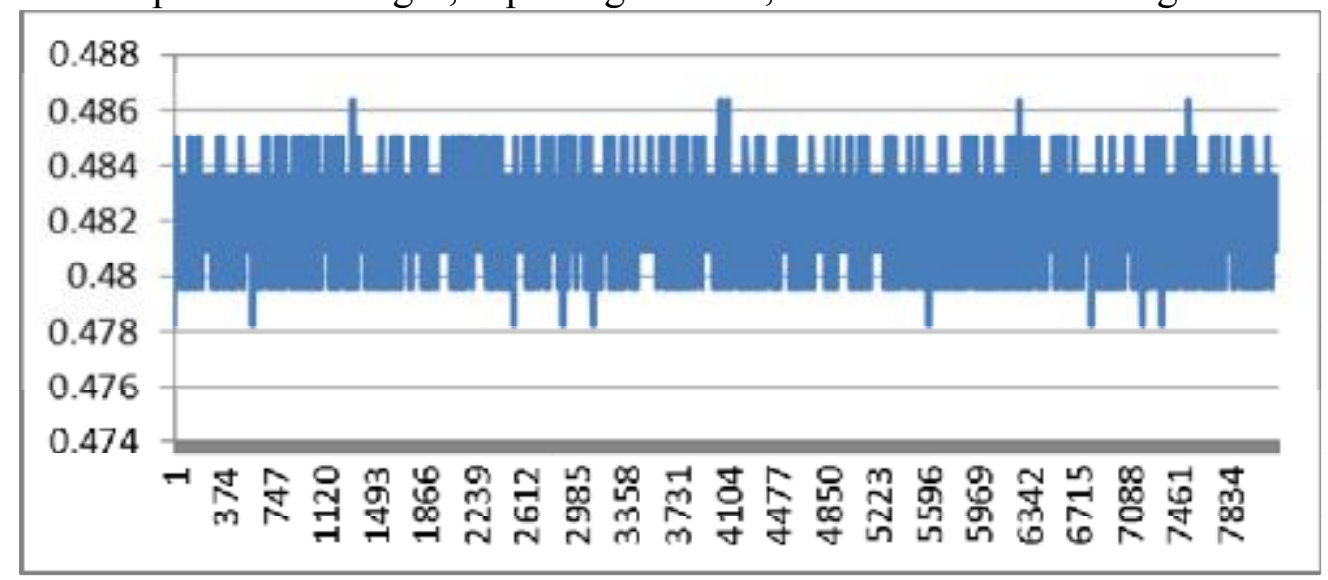

Fig.1 noise testing result

Setting the input as $1 \mathrm{~V}, 3 \mathrm{~V}, 5 \mathrm{~V}$ in sequence, capturing the output, the result is shown in figure 2 .

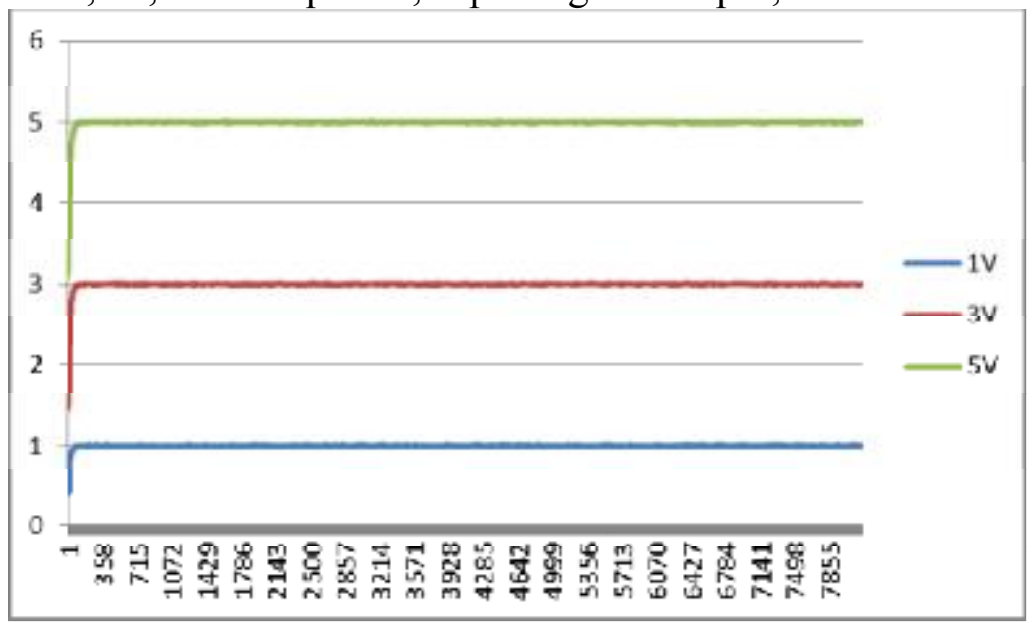

Fig 2. magnification times testing

Setting the input sine-likewise wave, then capturing the output, the result is shown in figure 3.

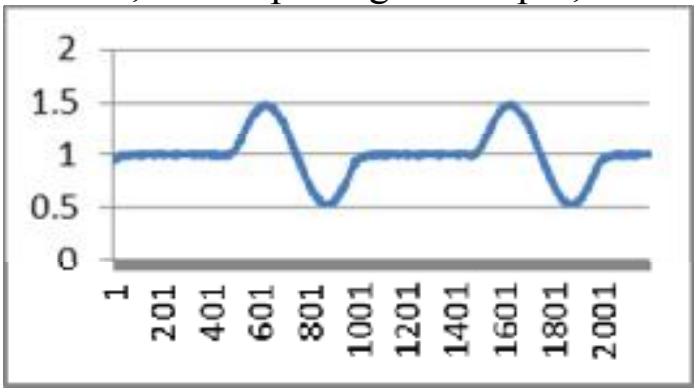

Fig 3. Variation signal testing result

We can get that the operational amplifier work in a good performance with perfect magnification and variation signal status, and a little noise.

There is another power board named used in NPS. The output is $24 \mathrm{~V}, 4 \mathrm{KHz}$ square wave normally. Common test doesn't contains frequency testing. Deep test introduces the frequency test to assess the performance of board. As to a good board, the test result is $4 \mathrm{Khz}$, for validating the effectiveness of the 
method, the capacitor $\mathrm{C} 115$ is removed from board which is related to output, the capturing the output, the result is $10^{100}$, that means it is infinite, which conforms the situation.

\section{Conclusions}

Now, the ICT technology is just testing the components, the paper introduce the deep test method, which can testing the partial function module, and can assess the performance of board more exactly. The case study above validates the effectives of the method, which is applied to NPS successfully.

While there are some problem need to be solved, such as some components cann't be test(oppocoupler, transformer).

\section{References}

[1] What's ICT test technology[J] . Electronics Quality. Vol.12. 34-34(2007).

[2] Rui Li, Jishi Guan, Xinglin Guan. The Research on Test Method of Nuclear Power Station Board Based on I3070[J]. Electronic Instrumentation Customers, 2012, 19 (1) : 70-72. 